\title{
Modality-specific imagery and associative learning in the deaf and hearing*
}

\author{
JAMES R. K. HEINEN \\ Old Dominion University, Norfolk, Virginia 23508 \\ and \\ WILLIAM A. STOCK and DEBORAH THARINGER \\ Arizona State University, Tempe, Arizona 85281
}

\begin{abstract}
Previous research has shown that recall performance of blind Ss is affected by auditory, but not visual word imagery, whereas the reverse is true for sighted Ss. The present study explored the possibility of a parallel effect with deaf Ss. Both deaf and hearing Ss learned lists of paired associates that were either high visual and low auditory imagery words or vice versa. It was predicted that deaf Ss would perform similar to hearing Ss with pairs of high visual imagery, but worse with materials of high auditory imagery. The results failed to demonstrate the expected interaction. Instead, performance was uniformly superior for the visual materials, and there was no significant difference between deaf and hearing Ss. Possible reasons for this outcome are discussed.
\end{abstract}

Paivio and Okovita (1971) and Bugelski (1971) have argued that the imagery interpretation of word imagery effects would be considerably enhanced if it could be demonstrated that effective imagery dimensions are related to whatever sense modalities are available to the learner. Pursuant to this end, Paivio and Okovita had congenitally blind and sighted Ss learn paired associate nouns which were rated high in either visual or auditory imagery. The authors reasoned that the congenitally blind cannot generate visual images of the referents of concrete words. Hence, purely "visual" words should be effectively abstract whereas words with referents that can be heard would be the concrete words of the blind. The results of the study demonstrated that the recall performance of the blind was positively affected by auditory, but not visual word imagery, whereas the reverse occurred for sighted Ss. A significant interaction of Pair Type by Sightedness led the authors to conclude that learning was mediated by modality-specific images evoked by the noun pairs. For the blind, then, it appears that the "mind's eye" is supplanted by the "mind's ear."

If imagery concreteness is indeed modality specific, it follows that the congenitally deaf should find it easier to learn noun pairs that are high in visual imagery than pairs high in auditory imagery. Such a case implies that purely auditory words should be effectively abstract, since the deaf presumably cannot generate auditory images of the referents of concrete words, whereas words with visual referents that can be seen would be the concrete words of the deaf. On the other hand, the recall performance of normal Ss on high auditory word pairs should exceed that of the deaf Ss because hearing

*This manuscript is sponsored by Robert C. Haygood, who takes full editorial responsibility.
Ss have the capacity to generate images of the referents of auditory words. Moreover, congruent with the results of Paivio and Okovita (1971), normal Ss should benefit more from visual than auditory imagery because of the importance of vision in their experiences with concrete objects and events and, hence, in the acquisition of concrete meaning. The task of this study was to test these hypotheses.

\section{METHOD}

\section{Design}

One factor, auditory acuity (AA), was factorially varied to form two experimental groups. Imagery modality (M) and trials (T) were varied as within-Ss factors across each factorial cell. The design was thus a $2 \mathrm{AA}$ (hearing vs deafness) by $2 \mathrm{M}$ (visual vs auditory imagery words) by $4 \mathrm{~T}$ (trials) mixed analysis of variance with repeated measures on the $M$ and $T$ variables.

\section{Subjects}

The Ss were 14 congenitally deaf students from the Arizona State School for the Deaf and the Blind in Tucson, Arizona, and 14 normal controls from Coronado High School in Scottsdale. Arizona. The two grouns were matched on age and intelligence. Ages ranged from $15-19(\bar{x}=17)$ years. The average WAIS performance score for the deaf Ss was 103 , and for the normal Ss, 108. All of the deaf Ss had a hearing loss of at least $60 \mathrm{~dB}$ in the best ear based on pure-tone audiometric evaluations. An approximately equal number of males and females participated in each group.

\section{Materials}

The stimuli consisted of 16 noun pairs, 8 of which consisted of nouns rated high in visual imagery but low in auditory and tactile imagery (hereafter referred to as high visual imagery pairs), and 8 which were high in auditory and low in visual and tactile imagery (high auditory imagery pairs). The nouns used were taken from three sources. Fifteen of the nouns were selected from a list of 579 nouns that had been rated by a group of Ss on visual, auditory, and tactile imagery using a seven-point 
Table 1

Means and Standard Deviations for Item Recall

\begin{tabular}{|c|c|c|c|c|c|c|c|c|}
\hline \multirow[b]{3}{*}{ Trial } & \multicolumn{4}{|c|}{ Deaf } & \multicolumn{4}{|c|}{ Hearing } \\
\hline & \multicolumn{2}{|c|}{ Auditory } & \multicolumn{2}{|c|}{ Visual } & \multicolumn{2}{|c|}{ Auditory } & \multicolumn{2}{|c|}{ Visual } \\
\hline & Mean & $\mathrm{SD}$ & Mean & SD & Mean & SD & Mean & SD \\
\hline 1 & 2.50 & 1.99 & 2.21 & 2.08 & 3.07 & 1.43 & 3.42 & 1.98 \\
\hline 2 & 4.50 & 2.21 & 5.21 & 1.84 & 5.00 & 1.83 & 5.57 & 2.34 \\
\hline 3 & 5.78 & 2.35 & 6.85 & 1.70 & 6.57 & 1.15 & 7.14 & 1.40 \\
\hline 4 & 6.57 & 2.17 & 7.07 & 1.68 & 7.42 & .75 & 7.71 & .72 \\
\hline
\end{tabular}

Note-Each mean is based on the recall performance of 14 Ss.

scale (Yuille \& Barnsley, 1969). Sixteen of the nouns were selected from a list used by Paivio and Okovita (1971) which they judged to be modality appropriate. Finally, one additional noun was similarly selected by the present authors. The resulting high visual imagery pairs were: rainbow-shadow, painting-cigar, tower-stain, blossom-blood, daybreak-green, meadow-hillside, star-poster, and circle-sky. The high auditory pairs were: music-gong, thunder-roar, echo-applause, click-conversation, scream-explosion, laughter-squeak, song-cough, and hum-whisper. It should be noted that 13 of the noun pairs used were identical to those employed by Paivio and Okovita (1971).

The word pairs were typed on $3 \times 5$ in. white filing cards in lower case letters. The recall materials consisted of a stapled booklet of 16 sheets, each one printed with the first member of a pair and an adjacent blank line.

\section{Procedure}

The Ss were tested individually after having been given standard paired associate instructions followed by one practice trial with three extra pairs. The instructions were administered orally to the hearing controls and were signed to the deaf Ss. The Ss were then given four alternating study and test trials. During study, E exposed each of the cards at 4-sec intervals timed to a series of beeps from a tape recorder. The pair members were reversed for each $S$, so that one $S$ received, for example, "song-cough" and another, "cough-song." Following each trial, the Ss were given the recall booklets and instructed to write the correct member that completed each pair. The Ss were permitted to work at their own pace, but were not allowed to turn back. A different random ordering of the items was used on each study and test trial.

\section{RESULTS}

A 2 AA by $2 \mathrm{MM}$ by $4 \mathrm{~T}$ mixed analysis of variance on recall scores yielded significance for the $\mathrm{M}[\mathrm{F}=5.45$, $\mathrm{df}=1 / 26, \mathrm{p}<.05]$ and $\mathrm{T}[\mathrm{F}=111.70, \mathrm{df}=3 / 78$, $\mathrm{p}<.0001]$ main effects. No other terms in the analysis reached significance. Table 1 lists recall means and standard deviations for high visual and high auditory word pairs across trials for the two experimental groups. Contrary to expectations, the crucial interaction between auditory acuity and pair type did not occur.

The data indicate that both groups recalled more high visual imagery word pairs than high auditory imagery pairs. It appears, then, that both the hearing and the deaf use the visual modality more easily than the auditory one. This conclusion is not surprising in that the visual mode tends to predominate in sighted persons. However, it had been expected that the deaf Ss would show greater impairment in the recall of high auditory imagery words than hearing Ss, thereby resulting in a significant Auditory Acuity by Word Modality interaction. An examination of the results revealed that the posited interaction was not significant. Some possible explanations for the absence of the interaction may involve the kinds of coding mechanisms available to the deaf Ss.

First, the deaf Ss in the present experiment were relatively sophisticated language users. The E noted that the deaf Ss consistently signed the word pairs upon presentation. This motor coding strategy may have compensated for any auditory deficiency and increased the recall of high auditory words to a level parallel to that of the hearing Ss. To assess the differential effects of modality-specific imagery words, future research may find it necessary to eliminate all forms of mnemonic coding other than visual and auditory imagery either by using Ss who cannot sign or by instructing them not to sign.

Second, the high imagery pairs used were selected because they met the criterion of being linguistically familiar to all Ss. The possibility exists that the deaf Ss were particularly attentive to the high auditory word pairs for the very reason that they had never experienced the referent sounds of concrete auditory words. This interpretation receives some support from their English teacher who indicated that the deaf Ss are unusually attentive to written material as a means of compensating for their handicap.

In summary, the hypothesis that recall of modality-specific imagery nouns would directly reflect the sense modalities available to an $\mathrm{S}$ was not supported in this experiment. The results were incongruent with those of Paivio and Okovita (1971) in their study of modality-specific imagery in the blind. When compared to hearing Ss, congenitally deaf Ss were not handicapped in their recall of high auditory imagery words. Perhaps deaf Ss who possess sufficient language skills are no more differentially response to word imagery modalities than hearing Ss. The data in this experiment appear to warrant this conclusion.

\section{REFERENCES}

Bugelski, B. R. The definition of the image. In Segal, S. J. (Ed.), 
Imagery: Current cognitive approaches. New York: Academic Press, 1971.

Paivio, A., \& Okovita, H. W. Word imagery modalities and associative learning in blind and sighted Ss. Journal of Verbal Learning \& Verbal Behavior, 1971, 10, 506-510.

Paivio, A., Yuille, J. C., \& Madigan, S. Concreteness, imagery, and meaningfulness values for 925 nouns. Journal of Experimental Psychology, 1968, 76(1, Pt. 2).
Yuille, J. C., \& Barnsley, R. H. Visual, auditory, and tactual imagery in paired associate learning. Paper presented at the International Congress of Psychology, London, England, July 1969.

(R eceived for publication July 25, 1974.) 